\title{
International agricultural research to reduce food risks: case studies on aflatoxins
}

\author{
Delia Grace $^{1}$ - George Mahuku ${ }^{2}$ - Vivian Hoffmann ${ }^{3}$. Christine Atherstone ${ }^{4}$. \\ Hari D. Upadhyaya ${ }^{5,6,7} \cdot$ Ranajit Bandyopadhyay ${ }^{2}$
}

Received: 21 January 2015 / Accepted: 26 March 2015 / Published online: 20 May 2015

(C) The Author(s) 2015. This article is published with open access at Springerlink.com

\begin{abstract}
Despite massive expansion of human and livestock populations, fuelled by agricultural innovations, nearly one billion people are hungry and 2 billion are sickened each year from the food they eat. Agricultural and food systems are intimately connected to health outcomes, but health policy and programs often stop at the clinic door. A consensus is growing that the disconnection between agriculture, health and nutrition is at least partly responsible for the disease burden associated with food and farming. Mycotoxins produced by fungi are one of the most serious food safety problems affecting staple crops (especially maize and groundnuts).
\end{abstract}

Special section series Strengthening the links between nutrition and health outcomes and agricultural research

Delia Grace

d.grace@cgiar.org

1 International Livestock Research Institute, PO Box 30709, Nairobi, Kenya

2 International Institute of Tropical Agriculture (IITA), Regional Hub for Eastern Africa, Plot 25, Mikocheni Light Industrial Area, Mwenge CocaCola Road, P.O. Box 34441, Dar es Salaam, Tanzania

3 International Food Policy Research Institute (IFPRI), 2033 K Street NW, Washington, DC 20006, USA

4 International Livestock Research Institute (ILRI), P.O. Box 24384, Kampala, Uganda

5 International Crops Research Institute for the Semi-Arid Tropics (ICRISAT), Patancheru, Telangana 502 324, India

6 Department of Agronomy, Kansas State University, Manhattan, KS 66506, USA

7 The UWA Institute of Agriculture, The University of Western Australia, Crawley, WA 6009, Australia
Aflatoxins, the best studied of these mycotoxins, cause around 90,000 cases of liver cancer each year and are strongly associated with stunting and immune suppression in children. Mycotoxins also cause major economic disruptions through their impacts on trade and livestock production. In this paper we use the case of fungal toxins to explore how agricultural research can produce innovations, understand incentives and enable institutions to improve, simultaneously, food safety, food accessibility for poor consumers and access to markets for smallholder farmers, thus making the case for research investors to support research into agricultural approaches for enhancing food safety in value chains. We first discuss the evolution of food safety research within the CGIAR. Then we show how taking an epidemiological and economic perspective on aflatoxin research connects health and nutrition outcomes. Finally, we present three case studies illustrating the traditional strengths of CGIAR research: breeding better varieties and developing new technologies.

Keywords Aflatoxins $\cdot$ Food safety $\cdot$ Health impacts $\cdot$ Market access

\section{Introduction}

Agricultural innovation has allowed massive expansion of human and livestock populations. Yet, as the world population passed 7 billion in October 2011, more than one billion people remain malnourished and more than 2 billion are sickened each year from the food they eat. Millions more die from diseases that emerge from, or persist in agricultural ecosystems: zoonoses (diseases transmissible between animals and man) and diseases recently emerged from animals make up $25 \%$ of the infectious disease burden in least developed 
countries and kill one in ten people who live there (Grace et al. 2012).

Other urgent health problems related to agriculture include fungal toxins (mycotoxins) in crops and animal source foods; plant toxins; use of wastewater for agriculture; misuse of agricultural chemicals and antibiotics; occupational hazards of working in food value chains; contribution of agriculture to climate change and impacts of this on disease; and health impacts of agricultural alteration of ecosystems (such as irrigation practices that promote malaria).

Agriculture thus has important effects on human health, but health policy and programs often stop at the clinic door while agriculture rarely has 'enhancing health' as an articulated objective. A consensus is growing that the disconnection between agriculture, health and nutrition is at least partly responsible for the disease burden associated with food and farming. The new CGIAR Research Program on Agriculture for Nutrition and Health (CRP A4NH) is attempting to bridge this disconnect.

This paper, based on a panel at the Independent Science and Partnership Council (ISPC) meeting in Bonn in 2013, uses risk mitigation and market access case studies around aflatoxins to explore how agricultural research can reduce the health risks from aflatoxin exposure for poor consumers while increasing the opportunities for poor farmers. We start with summarizing the evolution of food safety research within the CGIAR and then present case studies summarizing CGIAR research on aflatoxins. These case studies were chosen to show how risk based approaches, market based approaches and new risk mitigating technologies can help provide justification and add value to future CGIAR research on aflatoxins.

\section{CGIAR agricultural research on food safety and aflatoxins}

In 1971, due to serious concerns about global hunger, the CGIAR was formed and has had great success in carrying out agricultural research for developing countries. A landmark study in 2003 found that without CGIAR research, developing countries would be producing 7-8 \% less food and 15 million more children would be malnourished. For every $\$ 1$ invested in CGIAR research, $\$ 9$ worth of additional food is produced in developing countries (McClintock \& Griffith 2010). As of 2010 , around $40 \%$ of the total area planted for the world's 10 most important crops is planted with varieties resulting from CGIAR research (Renkow \& Byerlee 2010).

Food safety was not an initial focus of CGIAR research, with the first official mention in 2000 (Technical Advisory Committee 2000). However, 8 CGIAR centers had already started small-scale research related to food safety in the following areas: staple crops that resist pests (so farmers can reduce expensive, environmentally unfriendly and potentially food contaminating pesticides) (CIMMYT, IRRI, ICARDA, ICRISAT); aflatoxin resistant staples (CIMMYT, ICRISAT); biocontrol for aflatoxins (ICRISAT, IITA); ergot resistant sorghum (ICRISAT); reducing cyanide in cassava (CIAT) and milk quality and safety (ILRI)) (Kassam \& Barat 2003). In 2011, another survey of CGIAR food safety was conducted with more centers reporting food safety research. Aflatoxin research dominated but there was an expansion of risk assessment and prioritisation activities and substantial programs on the safety of perishables (animal source foods and vegetables), zoonotic diseases, occupational hazards and water associated diseases (A4NH 2011).

CRP A4NH conducted a series of prioritization exercises to help strategize its role in improving human health. The problems with the greatest impact on human health and livelihoods were diseases emerging from agro-ecosystems and foodborne disease due to microbial hazards. These agricultural associated diseases are responsible for almost $10 \%$ of the burden of human infections and non-infectious disease in least developed countries. The same prioritisation took into account the importance of agriculture-based solutions to agriculture associated human diseases and the track record of the CGIAR in delivering this research. Aflatoxins were identified as the most important human health concern associated with staple crops. Aflatoxins are toxic secondary metabolites produced by some species of the Aspergillus fungus. Not all species are toxigenic and when they are, the amount of toxin produced also varies. Aflatoxins are widespread in crops in tropical and subtropical regions, affecting more than 40 susceptible crops, especially maize and groundnuts, and are also found in dairy products and traditionally fermented foods. Ingestion of large amounts of toxin can cause death, and chronic exposure to aflatoxins leads to liver cancer and may contribute to enteropathy, maladsorption of nutrients, immune suppression and stunting.

\section{Case study: risk based approaches to aflatoxin control}

Risk analysis A risk-based approach to food safety focuses on the severity and likelihood of human health impacts. Risk analysis had already emerged as the internationally accepted approach for assessing food safety and trade issues (Lammerding and Fazil 2000; Vose 1998). It offers a systematic, science-based process for organizing and integrating quantitative and qualitative information about risks that incorporates steps of hazard identification and risk assessment, risk management and risk communication. ILRI has been developing methodologies for applying risk assessment to the data and resource scarce informal value chains in developing countries, conducting over 30 risk assessment and risk management studies (Grace et al. 2010). 
Risk ranking What cannot be measured cannot be managed and assessing the negative impacts (or burdens) of disease is an important step in determining how to allocate scarce resources to disease management. Risk ranking is the process of identifying and prioritizing the problems which may be present. The Global Burden of Disease, listing more than 100 major diseases in terms of their mortality and morbidity, is an example of risk ranking and a major advance in assessing the human health burden (Murray et al. 2001) that has led to more research investments being directed to high burden diseases. In the early 2000s, ILRI undertook a prioritisation of zoonotic diseases from the perspective of poverty (Perry et al. 2002) and subsequently prioritised diseases by their health burden on poor people (Grace et al. 2012). In terms of global disease burden, acute aflatoxicosis causes hundreds of deaths per year and chronic aflatoxicosis causes around 90,000 deaths a year from liver cancer. In comparison, the top ten causes of death (all preventable) cause on average 2.8 million deaths a year. Thus aflatoxin health impacts while not negligible, do not justify aflatoxins being a top public health priority. Better understanding and quantification of the health impacts of aflatoxin exposure can create a more convincing case for prioritizing the reduction of aflatoxin exposure, particularly in developing countries where uncontrolled exposure is highest.

Risk assessment The objective of risk assessment is to provide an estimate of the health impacts of a hazard with likelihood of their occurrence. This requires an assessment of the likely intakes (exposure assessment) and an evaluation of the known or potential health effects from human exposure (hazard characterisation) along with a dose response assessment.

Exposure assessment Chronic exposure to aflatoxins in many developing countries is well documented. From 85 to $100 \%$ of children in African countries have either detectable levels of serum AF-alb or urinary aflatoxins (Gong et al. 2002; Gong et al. 2003; Gong et al. 2004; Polychronaki et al. 2008; Turner et al. 2000; Turner et al. 2003; Turner et al. 2007; Wild et al. 1990; Wild et al. 1993). Several studies have also found $\mathrm{AFB}_{1}$ and $\mathrm{AFM}_{1}$ in excreted breast milk samples (Afshar et al. 2013; El-Tras et al. 2011; Gürbay et al. 2010; Jonsyn et al. 1995b; Polychronaki et al. 2006; Polychronaki et al. 2007; Sadeghi et al. 2009; Tchana et al. 2010).

Hazard characterisation The strongest association between chronic aflatoxin consumption and health impacts is the development of liver cancer. Each year 550,000-600,000 new liver cancer cases are recorded worldwide and approximately $25,200-155,000$ of these cases are attributable to aflatoxin exposure (Liu and Wu 2010). Hepatitis B virus (HBV) infection and chronic aflatoxin exposure places a person at 30 times greater risk for developing liver cancer than people who are HBV negative.
Aflatoxins are clearly associated with stunting and wasting. Children who are stunted often develop long-term development and cognitive problems and are more vulnerable to infectious diseases (Ricci et al. 2006). An estimated 170 million children under 5 years of age are stunted making this a major public health problem. A study in Benin and Togo found that stunted and/or underweight children had an average of 30 to $40 \%$ higher levels of aflatoxin adducts in their blood than children with a normal body weight (Gong et al. 2002). However, another study done in Benin and Togo found high levels were correlated with high prevalence of A. flavus and aflatoxin in groundnut, but this was not significant after adjustment for weaning status, agro-ecological zone and maternal socio-economic status (Egal et al. 2005). Other studies in the Gambia (Turner et al. 2007) and Kenya found significant association between aflatoxin exposure and wasting (Okoth and Ohingo 2004). Four studies (Abdulrazzaq et al. 2002; Abdulrazzaq et al. 2004; Abulu et al. 1998; Turner et al. 2007) reported a negative correlation between birth weight and aflatoxin levels; two studies found this relationship only when the sex of the infant was female (Jonsyn et al. 1995a; Vries et al. 1989).

Other studies show associations between aflatoxins and stillbirths (Lamplugh et al. 1988; Vries et al. 1989), liver cirrhosis (Kuniholm et al. 2008), jaundice in newborns (Abdulrazzaq et al. 2004; Abulu et al. 1998; Ahmed et al. 1995; Sodeinde et al. 1995) and immunosuppression (Jiang et al. 2005; Turner et al. 2003).

Attributing causation These known, probable and possible health impacts of aflatoxins illustrate the challenges in attributing causation. In epidemiology, if two factors are consistently and strongly associated (for example, aflatoxins in food and stunting) it can be because (1) one factor causes the other or (2) a third (or confounding factor) causes both. Correlation does not imply causation and epidemiology provides a set of tools to help understand whether association is causal or due to confounding. In the case of aflatoxins, epidemiologists look for:

- A temporal relationship in which the exposure precedes the disease development. Most studies on aflatoxin and stunting have been cross-sectional, but two studies have shown a temporal relationship (Gong et al. 2003; Gong et al. 2004).

- Biological plausibility as suggested by laboratory and animal studies. These show that aflatoxins have pathological effects on cells (including human cells) and metabolism. However, it is not known if the amounts consumed by children are enough to result in the proposed growth impairment effects.

- Animal studies showing health impacts. A large number of experimental studies have shown that aflatoxins lead to reduced weight gain in animals (Khlangwiset et al. 2011). However, in these studies aflatoxins were administered 
consistently at high to very high doses over short periods of time. Moreover, there is a very wide species variation in susceptibility to aflatoxins.

- Exposure that exceed thresholds necessary for effect. Most animal studies show a threshold below which effects are not seen but this is not constant across different studies (Khlangwiset et al. 2011). Species, strain, sex, age, diet, exercise and length of exposure all influence the threshold at which no effects are seen and the tolerance to higher doses. We do not know if the amount of aflatoxins consumed by children is over or under a threshold necessary to cause growth impairment.

- A dose response relation. Animal studies have shown a clear dose-response effect on weight gain, but only over a relatively high range of doses (Khlangwiset et al. 2011).

- Replication over studies. Some studies show associations between aflatoxins and growth outcomes but others do not (Leroy 2013).

Overall there is a strong case that aflatoxins cause stunting but the possibility of confounding has not been eliminated (Leroy 2013). There have been many examples in health where associations turned out to be non-causal. For example, billions of dollars were spent on unnecessary treatments and surgery for peptic ulcers because it was thought to be caused by stress and diet. However, most ulcers are due to an infectious agent (Centers for Disease Control and Prevention 2006). Because of these past mistakes, establishing causality requires high levels of evidence. The best way to demonstrate causality is by multiple, independent randomized controlled trials. There are many challenges to conducting these for aflatoxin exposure, but generating this evidence would lead to much greater engagement by the health community and investment by donors in aflatoxin management. IFPRI is addressing this research question.

Multiple burdens Agricultural-associated diseases often impose burdens across multiple sectors and assessing these facilitates understanding the full impact of the disease as well as in allocating the costs of control. ILRI has developed One Health and Ecohealth frameworks that provide ways to sum burdens of disease across the human, animal and agricultural environments and hence build a more convincing case for investment (Grace 2014).

Aflatoxins impose burdens on human health, animal health and productivity, the agriculture sector and the wider economy. Annual economic costs of mycotoxins to the U.S. agricultural economy were estimated to average $\$ 1.4$ billion and the annual cost of regulatory enforcement, testing and other quality control measures was $\$ 466$ million USD annually (Council for Agricultural Science and Technology 2003). In 2001, a study estimated that African food exporters lost $\$ 670$ million per year by not meeting EU safety standards alone
(Otsuki et al. 2001). However, Xiong and Beghin (2010) showed that the standards set by the EU had no significant trade impact on groundnut exports from Africa across various methods of estimation. Their findings concluded that the trade potential of African groundnut exporters is more constrained by domestic supply issues - such as quality, consistency and delivered cost - than by limited market access. African exports were already declining and African exporters would likely not have met the earlier less restrictive standards either (Roy 2013).

\section{Conclusion}

A better understanding of health impacts of aflatoxins, the risk posed from different products in different contexts and the economic costs of aflatoxins across human health, the livestock industry, the agricultural industry and trade would motivate greater investment in aflatoxin assessment and control.

\section{Case study: market based approaches to aflatoxin control}

A major incentive for farmers to invest in aflatoxin risk mitigating technologies and practices is provided when maize, groundnuts or other crops with low levels of aflatoxin can be sold for a higher price than the same crops with high or unknown levels of aflatoxin. These differentiated markets are rare in developing country domestic markets but common for exports or international food aid programs such as the World Food Program (WFP) (Méaux et al. 2013). A second type of differentiated market is where grains are used as inputs into other production processes, for example, as animal feed in the production of meat or milk, where there is a perceptible economic benefit associated with use of low-aflatoxin maize or groundnuts.

Food systems in poor countries are typically dominated by the informal sector (Grace et al. 2010), consisting of many small firms that operate outside of government control. The presence of a large informal sector presents several challenges to the provision of safe food in such countries. First, the operation of a large part of the market outside of any regulatory strictures implies that regulatory measures have no impact on much of the food supply. Second, informal competitors put pressure on formal sector firms, who must comply with regulations - to the extent these are enforced - while remaining price-competitive. Third, the small scale of these informal firms, many of which supply the formal sector, implies that ensuring food safety at each transaction is prohibitively costly. Finally, the anonymity of informal market actors beyond their immediate customers implies that food safety incidents have little impact on reputation and thus firms have little incentive to invest in improving food safety. At the same time, the informal sector provides a livelihood for most small-scale 
producers and food for most poor consumers; informal sector food is typically cheaper and more accessible than formal sector alternatives and often is no worse in meeting food safety standards (Grace et al. 2010).

Market chains The Kenyan maize market serves as an example. Each link in this market chain, from farmer to retailer, is characterized by a mix of both formal and informal firms. The formal and informal sectors are not isolated: a formal maize miller may obtain inputs from an informal trader or from a formal trader who obtains the maize from informal farmers. Multiple traders may be involved in moving grain from farm to mill, first aggregating grain from many small farmers in the region of origin, then moving it across country to the miller either to a large scale mill, or to disaggregators in the destination market, who supply informal retailers (Kirimi et al. 2011). The large number of small-scale transactions, particularly at the farm gate, where the majority of grain is supplied by farmers operating five acres of land or less (Guantai and Seward 2010) makes testing for food safety at each point of transaction prohibitively costly.

High rates of aflatoxin contamination have been found to exist in both informally sold and commercially milled maize in Kenya. Lewis et al. (2005) found that $55 \%$ of maize flour and kernels purchased in districts affected by a recent aflatoxicosis outbreak were contaminated above the allowable limit at that time, with $35 \%$ containing over five times the regulatory limit, and $7 \%$ containing over 20 times the limit. There was no significant difference in contamination rates between maize obtained from informal, open-air markets versus formal sector retailers, or maize that had been milled versus sold in kernel form. More recently, reports indicated that samples from $65 \%$ of 20 major formal sector mills were contaminated beyond the regulatory limit (Gathura 2011).

According to interviews conducted by IFPRI with the managers of medium and large scale maize mills in Kenya, several of these mills now expend significant resources to test incoming grain for aflatoxin (Moser et al. 2014). These efforts were, according to the managers interviewed, partially inspired by the negative publicity suffered by the industry as a whole after the 2011 report. Data collected in 2013 show that more expensive brands of maize flour are less likely to exceed the regulatory limit for aflatoxin (Moser et al. 2014). This could be due to the fact that firms with a strong brand reputation, which are thus able to charge a higher price, are more careful in their selection of grain, as they have more to lose if it is discovered that their flour is contaminated, or if their product is implicated in a food safety incident.

Willingness to pay While food safety is not an attribute currently used in the marketing of maize flour, credible assurance of product safety could potentially be a profitable strategy. A small-scale experiment found that Kenyan maize consumers in eight rural villages were willing to pay an average of $7 \%$ more for aflatoxin tested maize (Hoffmann and Gatobu 2014). An on-going IFPRI study seeks to measure consumer response to the introduction of an aflatoxin tested, third party verified maize flour, and the impact of marketing messages on demand for such flour over time, under more natural market conditions in a larger sample.

Challenges The danger, however, of relying exclusively on market-based approaches to food safety is that the poorest, most price-sensitive consumers will not be able to afford safe food. At worst, these consumers could be made worse-off, if the safety of particular products is achieved simply by firms rejecting inputs that do not meet safety standards. The food rejected by these firms will then be concentrated in lowervalue segments of the market, increasing the level of contamination in the lowest-cost food.

This worst-case scenario can be avoided if food safety standards are achieved through a reduction in aflatoxin contamination, whether during cultivation, storage, transport or processing, rather than through a sorting strategy alone. Technologies for reducing contamination levels at each of these stages are either available or in development (Wu and Khlangwiset 2010b). Inducing farmers, traders, and processors to adopt these technologies requires that these actors receive some benefit from doing so. If consumers are indeed willing to pay more for safer food, then processors have an incentive to pay a premium for safer inputs. This can in turn induce traders to take greater care to preserve the quality of maize they handle, and to seek out farmers who use recommended practices, including resistant seeds, biocontrol, good agricultural practices (GAP), careful drying and improved storage structures. Finally, farmers will adopt these technologies if the cost of using them is justified by the price premium they receive from selling safe maize.

The transmission of the food safety premium paid by the final consumer to that received by the farmer relies on the observability of aflatoxin contamination at each stage in the market chain. Low-cost, field-ready detection methods are not currently available. The large number of market actors typically involved from farm to plate in such contexts is an added challenge. Shortening market chains, so that farmers or farmer organizations sell directly to processors, could potentially reduce the number of tests required and thus the cost of ensuring safety.

Enabling traders Another approach, currently being developed through USAID's Feed the Future program in Uganda, is to give traders both the incentives and tools to help small farmers improve the safety of the maize they sell. Under this approach, village-level traders are trained on the best agronomic practices to both increase yields and prevent aflatoxin. 
These traders are linked to agricultural input suppliers, and offer farmers advice, inputs and services such as application of pesticides during cultivation, and drying of maize at harvest. Traders are then able to sell maize meeting USAID's standards at a premium price. While this approach is promising, food aid will always constitute a small portion of the maize market. Private sector involvement is crucial to achieving results at any significant scale.

Building awareness In a weak regulatory environment such as the Kenyan maize flour sector, the introduction of credible food safety information, for example by independent third party testing, could be catalytic. Consumer awareness of aflatoxin in Kenya is relatively high, due to periodic media reports of deaths due to aflatoxicosis, and contamination in the commercial maize supply. Once one firm adopts a marketing strategy based on the assurance of food safety, others may follow suit to remain competitive. This could in turn induce more effective regulatory enforcement, as local capacity for testing and monitoring is built. However, at least in developed countries, commercial firms have been reluctant to use food safety as a marketing strategy.

\section{Conclusion}

Market-based approaches have shown promise in providing a funding mechanism for aflatoxin control. However, as noted above, in the presence of a large informal sector, which will continue to be unregulated, there is a danger that a reduction in aflatoxin contamination at the high end of the market would come at the cost of increased contamination at the low end. For this reason, identifying and promoting ways for firms to cost-effectively reduce aflatoxin in the fields and storehouses of their suppliers, rather than simply rejecting contaminated grain at the mill gate, is key to achieving the public health goals associated with improvements to food safety.

\section{Case study: biocontrol, an effective and environmentally safe technology for reducing aflatoxins}

Contamination of crops with aflatoxins is a complex process resulting from environmental and biological factors such as crop host, insects and microbial population. Biological control is a proven method of controlling several plant diseases. Narrowly defined, "biological control refers to the purposeful utilization of introduced or resident living organisms, other than disease resistant host plants, to suppress the activities and populations of one or more plant pathogens" (Pal and McSpadden-Gardener, 2006). Several biological control agents such as bacteria and Trichoderma species have been evaluated for the reduction of aflatoxins in groundnut during the pre-harvest stages (Anjaiah et al. 2006). The "competitive exclusion" based biological control approach (Cotty and Bayman 1993) is widely used by farmers in the US (Cotty et al. 2008) and has more recently been used in Africa (Bandyopadhyay and Cotty 2013).

In the natural environment, some strains of Aspergillus species produce toxins while others do not (atoxigenic strains) (Atehnkeng et al. 2008a). Competitive exclusion entails introducing native atoxigenic strains in the fields before the increase of normal Aspergillus populations (Cotty 1994). The population of introduced atoxigenic strains preferentially occupies the food substrates in the field first, thereby outcompeting other resident strains, including toxigenic strains, resulting in products with reduced aflatoxin. The atoxigenic strains survive from year to year and are effective on several crops thus providing multi-year and multi-crop benefit. Application of atoxigenic strains does not increase the total Aspergillus population (Atehnkeng et al. 2014).

Strain identification method Atoxigenic biocontrol strains are selected using microbiological, DNA and field-based research to ensure that the strains are safe and persistent and provide effective and long-lasting reduction in aflatoxins (Atehnkeng et al. 2013). First, approximately 500 georeferenced crop samples are collected from the target country or region for which the biocontrol product is to be developed. From these samples, several thousand isolates of Aspergillus are obtained. Using a series of lab- and field-based selection protocols, biocontrol strains are selected that: 1) cannot produce the toxin on any substrate; 2) have defects in genes governing the aflatoxin biosynthetic pathway; 3) belong to genetic groups solely consisting of atoxigenic strains, 4) are able to reduce aflatoxin by $>90 \%$ when co-inoculated with high toxin producers on maize grains; 5) have wide distribution and adaptation; 6) have superior capacity to colonize, multiply and survive in soil and crop debris; 7) are frequently found in grains; and 8) have superior capacity to reduce aflatoxin in the field. The best strains are finally selected to constitute the biocontrol product.

Development of aflatoxin biocontrol in Nigeria IITA started biocontrol research in Africa in the Republic of Benin in late 1990s with funding from the German government. In 2003, the biocontrol effort moved to Nigeria with continued funding from the German government and in collaboration with USDA-ARS and University of Ibadan. Initially, more than 4200 Aspergillus strains collected from maize and soil samples in Nigeria were tested and approximately 20 atoxigenic genetic groups were selected (Donner et al. 2010). The atoxigenic groups were evaluated for growth rate, sporulation, and competitiveness in vitro and in vivo (Atehnkeng et al. 2008b). Information generated from strain characterization work led to the identification of several candidate atoxigenic strains for field evaluation. 
Field efficacy of an experimental formulation consisting of four native atoxigenic strains was evaluated on maize in 2007 and 2008 in four agro-ecological zones in Nigeria. Grains from treated and untreated fields were analyzed for aflatoxins at harvest and after storage. Frequency of occurrence of the four atoxigenic strains in grains at harvest was quantified using vegetative compatibility analyses. Application of the strain mixture resulted in reduced aflatoxin content and significantly increased the combined frequencies of the applied strains recovered from the soil and grain (Atehnkeng et al. 2014). Aflatoxin reductions of 67$95 \%$ were associated with a 74-80\% combined incidence of the four atoxigenic strains on the treated crops. The results suggest that the evaluated multi-strain formulated product has potential to contribute to reduced aflatoxin contamination in Nigeria. This was the first report of a field evaluation of an endemic strain mixture effective at reducing aflatoxin contamination during crop development (Atehnkeng et al. 2014).

The product, trademarked Aflasafe ${ }^{\mathrm{TM}}$, is registered with Nigeria's National Food and Drug Administration and Control (NAFDAC). The optimum rate of application of the product is $10 \mathrm{~kg} / \mathrm{ha} 2-3$ weeks before plant flowering. Aflasafe $^{\mathrm{TM}}$ works equally well in reducing aflatoxin in both maize and groundnut. Field testing of Aflasafe ${ }^{\mathrm{TM}}$ in Nigeria by about 3000 farmers between 2009 and 2013 consistently showed a decrease in contamination in maize and groundnut by $80-90 \%$ or more. The Bill \& Melinda Gates Foundation funded the construction of a demonstration-scale manufacturing plant with a capacity to produce $5 \mathrm{t}$ of Aflasafe ${ }^{\mathrm{TM}}$ per hour in Nigeria.

Cost-effectiveness $\mathrm{Wu}$ and Khlangwiset (2010a) concluded that bicontrol of aflatoxin is one of the most costeffective aflatoxin control methods, with the potential to offer a long-term solution to aflatoxin contamination in Africa. Currently, Aflasafe ${ }^{\mathrm{TM}}$ costs US $\$ 18.75 /$ ha (dosage: $10 \mathrm{~kg} / \mathrm{ha}$ ) and provides protection from aflatoxin in the field and during storage.

Scaling up in Nigeria In 2012, G20 leaders launched a new initiative - AgResults - which included Aflasafe ${ }^{\mathrm{TM}}$ in Nigeria as one of the first three pilot projects to encourage the scaling up of agricultural technologies by smallholder farmers. The goal of the AgResults Aflasafe ${ }^{\mathrm{TM}}$ pilot project is to incentivize adoption of Aflasafe ${ }^{\mathrm{TM}}$ and jumpstart the availability of 260 , $000 \mathrm{t}$ of low-aflatoxin maize by 2017 , equivalent to around $3 \%$ of current maize production in Nigeria, of which $60,000 \mathrm{t}$ are estimated to be consumed on-farm and 200,000 would be sold in markets. However, whether a more significant share of total maize production than $3 \%$ can be achieved even in Nigeria where the initiative began in Africa, and whether large-scale introduction and adoption can be stimulated and replicated all across the continent, remains to be seen at the time of writing.

AgResults Aflasafe ${ }^{\mathrm{TM}}$ pilot works with private or public sector enterprises (also called implementers) that can organize smallholder farmers into groups and take advantage of economies of scale from collective action. The project provides training on production of lowaflatoxin maize and health information for farmers as well as information to buyers of maize. The implementers provide inputs and farm services to their constituent farmers at cost. Farmers use high-yielding seeds and fertilizers to boost productivity, Aflasafe ${ }^{\mathrm{TM}}$ to improve quality and are trained in GAPs. The implementers purchase and aggregate maize from their constituent farmers and develop market linkages with buyers seeking aflatoxin-safe maize (e.g., the poultry industry and premium food sector) and negotiate a premium over the market price. Aflatoxin concentration in the aggregated maize is quantified to assure quality. Maize from aggregation points are sampled and tested microbiologically (Atehnkeng et al. 2014) for the presence of high frequency of Aflasafe ${ }^{\mathrm{TM}}$ strains to verify if the maize was harvested from aflasafe-treated fields. The implementers receive an incentive of $\$ 18.75$ for every ton of aggregated maize containing high frequency of Aflasafe ${ }^{\mathrm{TM}}$ strains. Therefore, the implementers, and farmers through them, receive incentives from the market and also from the AgResults project. In 2013, the implementers sold their low-aflatoxin maize at 2.8 to $13.5 \%$ premium over the prevalent market price and realized up to $510 \%$ return on investment. Aflasafe ${ }^{\mathrm{TM}}$ incentives from the AgResults project were a bonus. In addition, farmers kept about $40 \%$ of their harvest for home consumption thereby improving safety of home-grown food. The example above demonstrates that in principle it should be possible to profitably scale up adoption of Aflasafe ${ }^{\text {TM }}$ by smallholder farmers through a mix of technical (aflasafe and other management practices), institutional (famer groups and premium markets) and policy (incentivization) innovations (A4NH 2014).

Scaling out in other countries The excellent efficacy of biocontrol in reducing aflatoxin in Nigeria has led to the expansion of biocontrol research in Burkina Faso, Ghana, Kenya, Mozambique, Senegal, Tanzania, and Zambia. In 2014, testing of the Senegalese product Aflasafe SN01 was extended to The Gambia. The biocontrol product Aflasafe SN01 can potentially reinstate groundnut exports to the European Union lost by Senegal and The Gambia due to aflatoxin contamination. Country-specific products are currently under development for Rwanda, Burundi and Uganda. Maize and groundnut are the target crops in all countries except Kenya where the emphasis is solely on maize. Most of the scaling out efforts are 
funded by the US and Austrian governments and the Bill \& Melinda Gates Foundation.

\section{Conclusion}

Biocontrol for aflatoxins is an environmentally friendly and effective technology. Adapting the biocontrol technology initially developed by USDA-ARS, the CGIAR has conducted laboratory work on strain identification and has continued to pilot test in farmers' fields, as well as investigating large-scale manufacturing and product use by thousands of farmers. As with other agricultural inputs such as hybrids, fertilizers and pesticides, farmers need to purchase biocontrol products. There are challenges for adoption of biocontrol as biocontrol products do not increase yield but improve food quality and public health which are not easily perceived. Bundling biocontrol with GAPs, to improve crop yield, is one way to increase adoption. Going to scale will require overcoming the logistic and adoption barriers and developing premium markets to incentivize farmers to use biocontrol or subsidizing biocontrol use on public health grounds. From the present experience, it appears that it is possible to overcome constraints to adoption through innovative approaches.

\section{Case study: breeding for aflatoxin resistance in tropical maize}

Maize is the most important cereal crop in sub-Saharan Africa and an important staple food for more than 1.2 billion people in sub-Saharan African and Latin America. Several management strategies may reduce aflatoxin contamination of maize. However, a promising innovation for elimination of aflatoxin is to breed for host resistance to aflatoxin accumulation. Host resistance is generally considered an important, safe and preventative strategy that is economical, easy to disseminate, requires no additional production or management resources, leaves no harmful residues and is compatible with other control measures, including biological control.

Understanding resistance The Aspergillus fungi that produce aflatoxins occur with higher incidence when maize is grown under stressed conditions. Late-season drought and high temperatures during kernel filling (Cairns et al. 2013; Lisker and Lillehoj 1991; Widstrom et al. 2003) and insect or mechanical damage to kernels (McMillian et al. 1985) can increase infection rates. Development of aflatoxin resistant varieties may include direct selection for resistance to the fungus and aflatoxin accumulation, indirect selection for resistance or tolerance to abiotic and biotic stresses, or selection for morphological traits such as ear, kernel, and husk characteristics that impede or delay fungal infection or growth (Warfield and Davis 1996; Widstrom 1987). Sources of resistance to many of these factors have been identified and are now being combined to develop aflatoxin resistant maize germplasm adapted to various agro-ecologies.

Tools to identify resistant germplasm Selection of genetic factors influencing resistance to $A$. flavus and aflatoxin accumulation relies on the ability to create adequate and uniform disease pressure, high throughput phenotypic screening capacity, and inexpensive, robust methodologies for aflatoxin analysis. The development of the laboratory kernelscreening assay (Brown et al. 1999) method has enhanced identification of maize germplasm with resistance to A. flavus and aflatoxin accumulation and is used to complement field evaluations (Menkir et al. 2006).

Aflatoxin detection Because aflatoxins are toxic at very low levels, detection methods must be very sensitive and accurate. Although different methods can be used to detect and quantify aflatoxin levels (Krska et al. 2008), an inexpensive, robust and high throughput method is needed for large scale breeding programs. The bright green yellow fluorescent light technique can quickly detect maize lines supporting high fungal growth levels (Shotwell and Hesseltine 1981). A cost-efficient, inhouse ELISA technique developed by ICRISAT has been adapted at CIMMYT for routine detection and quantification of aflatoxins in breeding programs. This assay costs approximately US\$2-3 per sample and has allowed large scale screening of segregating populations, a vital component of breeding for reduced aflatoxin accumulation.

Generation of resistant germplasm Breeders must combine multiple sources of resistance into adapted germplasm, a task made more difficult by the large number of genes controlling A. flavus and aflatoxin resistance and the large genotype by environment interaction generally associated with aflatoxin resistance (Campbell and White 1995; Widstrom et al. 2003). Resistance to A. flavus and aflatoxin accumulation may be achieved via: (i) prevention of fungal infection of maize; (ii) prevention of subsequent growth of the fungus once infection has occurred; (iii) inhibition of the formation of aflatoxin, following infection; and, (iv) degradation of aflatoxin by the plant or the fungus. Germplasm with promising levels of resistance to both $A$. flavus and aflatoxin accumulation has been identified and quantitative trait loci (QTL) for both traits have been mapped (Brooks et al. 2005; Busboom and White 2004; Warburton et al. 2011; Willcox et al. 2013). Marker assisted selection using markers linked to genes or QTL associated with aflatoxin resistance may enhance breeding progress and enable rapid selection gains during resistance breeding (Brooks et al. 2005; Paul et al. 2003). Doubled haploid (DH) technology (Geiger 2009), can also be used to rapidly develop inbred lines combining aflatoxin resistance with other important agronomic traits. The DH technology allows development of inbred lines in 2 to 3 seasons, compared to the 
6 to 8 seasons required using conventional breeding techniques. This technique has allowed the rapid introgression of A. flavus and aflatoxin resistance into adapted germplasm and has expedited the development of lines with acceptable levels of aflatoxin resistance. To date, CIMMYT has generated 4000 doubled haploid maize lines from sources of ear rot resistance, drought, and heat tolerance. These doubled haploids are being evaluated by breeding programs to identify new superior lines combining aflatoxin resistance and good agronomic performance under drought and heat stresses.

\section{Conclusion}

Accumulation of aflatoxins in maize occurs following a complex series of interactions between maize genotype, environment, pathogen genotype, and crop management practices. Selection must be simultaneous for multiple stresses to combine drought and heat tolerance, resistance to insects (especially ear feeding insects), pathogen resistance including A. flavus and aflatoxin accumulation, plus any other diseases endemic to each growing area. All of these biotic and abiotic stress tolerances must be combined with improved agronomic performance in hybrids in order to stimulate adoption of aflatoxin resistant materials. Farmers will not grow low yielding hybrids regardless of aflatoxin resistance, as the toxin itself is invisible to the naked eye and only a few selected end-uses (such as animal feeds, baby foods, confectionery and high-end millers) regularly test for it and provide incentives or penalties that would induce higher production of low alflatoxin maize by farmers. With regard to home use, the negative impact of aflatoxin consumption is generally slow and difficult to recognize, whereas hunger due to insufficient food is immediate and pressing. The challenge is to systematically identify and introduce the best sources of resistance into adapted maize germplasm available in areas where aflatoxin contamination is a problem. Established procedures for field inoculation, measurement of aflatoxin levels, and generation of doubled haploids, have resulted in the development of an array of resilient maize germplasm and may lead to more opportunities for efficient development of aflatoxin resistant elite hybrids. Currently, promising new germplasm is being tested in different hybrid combinations and in different environments of Africa, especially Kenya, where aflatoxin contamination has been a problem.

\section{Case study: breeding to reduce aflatoxin contamination in groundnuts}

Millions of smallholder farmers in sub-Saharan Africa grow groundnuts as an important source of protein and as a cash crop. Groundnuts are prone to aflatoxin contamination and because they form a large part of the diet in many parts of Africa, represent a significant source of aflatoxin exposure. The use of resistant cultivars is one strategy to reduce aflatoxin contamination in the field. To provide incentive for better farmer adoption of resistant cultivars, ICRISAT has developed varieties with other superior agronomic traits - higher pod yield, drought resistance, and short duration - that increase farmer's yields while also lowering aflatoxin contamination risk.

Screening methods for aflatoxin resistance Pod wall, seed coat, and cotyledons influence the seed infection and aflatoxin contamination in groundnut. Resistance of the pod wall is attributed to pod shell structure, while resistance of the seed coat is due to thickness and density of palisade layers, presence of wax layers, and absence of fissures and cavities. In vitro seed colonization (IVSC), pre-harvest seed infection, and aflatoxin contamination are important ways to identify aflatoxin resistance in germplasm. Field screening can be done either in sick plots or in a location where aflatoxin contamination events are more common (hot spot location). Pods at harvest are separated manually, dried and shelled to collect a representative sample for estimating aflatoxin using indirect competitive ELISA (Waliyar et al. 2005) or other approved methods. Identification of resistance to IVSC is a commonly used laboratory screening method wherein a toxigenic isolate of $A$. flavus or a mixture of toxigenic isolates is used (Thakur et al. 2000).

Sources, mechanism (barriers) and genetics of resistance to aflatoxin contamination Both additive and/or nonadditive genetic variance control resistance to $A$. flavus and/or aflatoxin production in groundnut (Ozimati et al. 2014; Xue et al. 2004). Sources of all the three types of resistance (preharvest seed infection, in vitro seed colonization, and aflatoxin production) have been reported (Nigam et al. 2009; Waliyar et al. 1994), and in spite of high genotype by environment interaction, a number of germplasms with high levels of resistance across environments have been identified (Nigam et al. 2009). More importantly, some of the germplasm lines contained very low aflatoxin $(0.4-1.0 \mathrm{ppb})$ in comparison to high levels (171-305 ppb) in susceptible controls. Clearly, more and precise studies are needed to determine the inheritance of resistance mechanisms to determine allelic relationship among resistance components for developing knowledge-based breeding strategies to breed cultivars with higher levels of resistance.

Progress in breeding for resistance to aflatoxin Researchers at ICRISAT and elsewhere were able to combine resistance to pre-harvest seed infection and/or aflatoxin production into improved genetic backgrounds (Rao et al. 1995; Upadhyaya et al. 2001; Upadhyaya et al. 2003; Waliyar et al. 1994; Zhou et al. 2002). A number of breeding lines showed much less preharvest aflatoxin contamination levels $(0.2-4.1 \mathrm{ppb}$ seed $)$ than susceptible control under ambient conditions.

Current breeding research at ICRISAT is focused on development of breeding lines combining early maturity, tolerance to terminal drought and resistance to seed infection and 
aflatoxin contamination. A number of breeding lines combining short duration and aflatoxin resistance were identified for further evaluation. Some of these varieties in advanced trials were significantly superior $\left(2.8-4.8 \mathrm{tha}^{-1}\right.$ pod yield $)$ over the control J 11 (2.1 t ha ${ }^{-1}$ pod yield). ICGV 10038 (4.5 $\mathrm{t} \mathrm{ha}^{-1}$, $5 \mathrm{ppb}$ aflatoxin content and $5 \%$ A. flavus infestation), and ICGV 10043 (4.0 t ha ${ }^{-1}, 15 \mathrm{ppb}$ aflatoxin content and $2 \%$ A. flavus infestation) were the best performing entries for pod yield and aflatoxin contamination. Furthermore, ICGVs 13124,13125 , and 13127 combined short duration and resistance to aflatoxin contamination into improved genetic background (ICRISAT 2012/2013).

Genomic resources in groundnut Recent developments at ICRISAT and elsewhere have changed the status of groundnut as a genomic resources rich crop (Pandey et al. 2014) and this knowledge is being applied to identify molecular markers associated with resistance to aflatoxin in groundnut.

\section{Performance of aflatoxin resistant varieties in farmers'}

fields In a period from 2003 to 2007, advanced varieties with aflatoxin resistance, were evaluated for seed infection/ pre-harvest aflatoxin contamination and for agronomic performance in farmer participatory, multi-location on-farm trials in India and also for 2 years (2008 and 2009) in farmers' fields in Mali, West Africa. The aflatoxin contamination for 2 years (2003 and 2004) evaluation in India ranged from 0 to $7 \mathrm{ppb}$ across locations compared with 0 to $>150 \mathrm{ppb}$ in a susceptible control. $1 \mathrm{n} 2005$, the resistant varieties produced $16-61 \%$ higher pod and haulm yields coupled with 36-73\% reduction in aflatoxin contamination over the control. Further field evaluations indicated a reduction in pre-harvest aflatoxin contamination by $57-$ $71 \%$ and $60-75 \%$ over the control during 2006 and 2007 , respectively. Importantly, a number of these varieties were also found adapted to West African (Mali) conditions and had low levels of pre-harvest aflatoxin contamination, with four varieties having $<5 \%$ seed infection. Seed infection by A. flavus varied from $2.2 \%$ (55-437, resistant control) to $94.81 \%$ (JL 24, susceptible control), while aflatoxin contamination varied from $2.9 \mathrm{ppb}$ (ICGV 94379) to $957 \mathrm{ppb}$ (JL 24).

\section{Conclusion}

Resistance to pre-harvest seed infection and aflatoxin contamination has been successfully introgressed into improved genetic backgrounds, and such varieties performed exceedingly well in India and Mali. However, these are not completely free from aflatoxin contamination. Use of resistant varieties together with integrated crop management and postharvest technologies could greatly minimize the risk of aflatoxin contamination in groundnut.

\section{Overall conclusions}

The CGIAR has been highly successful in conducting agricultural research, especially in the development of crop varieties that enhance productivity and reduce hunger. However, the challenges of the 21 st century are different from those of the 20th. There have been enormous improvements in reducing the proportion of people suffering hunger and in improving education, health and life expectancy. But because of population growth, absolute numbers of people suffering hunger and micronutrient deficiencies remain high. Moreover, as agriculture intensifies and expands to feed more people, the negative impact of agriculture on ecosystems and health are accentuated. In addition, some places, primarily in Africa, have yet to see the benefits of CGIAR research at scale. The persistence of old and emergence of new challenges has led to re-assessment of the role of the CGIAR. A far-reaching reform process was set in motion, leading to complete reorganization and a new set of programs, the CGIAR research programs, was initiated in 2012. These new programs plan to add value by building on the traditional strengths of CGIAR research by improving coordination and filling gaps and developing impact pathways from research to development outcomes.

This paper details some CGIAR successes in areas of traditional strengths: risk based approaches, market based approaches, crop genetic improvement and biocontrol to control aflatoxins. At the same time, the paper suggests that in the relatively complex problem of aflatoxins, supply side solutions are not enough. By incorporating perspectives from economics and epidemiology, evidence can be generated to drive farmer adoption, distribution models and market development and incentives, important steps in the impact pathways identified to ensure CGIAR research goes to scale.

Priority research activities include:

1. Generating evidence on the human and animal health impacts of aflatoxins

2. Understanding the potential of improved technologies and good agricultural practices to reduce aflatoxin exposure in farm households and communities

3. Assessing the costs and benefits of proposed strategies on aflatoxin reduction as well as other goals such as income and food security

4. Assessing how costs and benefits are distributed across men and women in households and across different types of households in communities

5. Understanding factors that facilitate and constrain adoption of aflatoxin control strategies would also be assessed, with particular emphasis on gender issues, incentives and on the role of health information and communication. 
Acknowledgments We acknowledge the contribution of Joseph Atehnkeng, Adebowale Akande, Lawrence Kaptoge, Charity Mutegi, Joao Augusto and Juliet Akello from IITA; Peter Cotty at the United States Department of Agriculture; and, Farid Waliyar and Hari Sudini from ICRISAT. Support for writing this paper was provided by the CGIAR Research Programs on Agriculture for Nutrition and Health, Grain Legumes and Maize.

Conflict of interest The authors declare that they have no conflict of interest.

Open Access This article is distributed under the terms of the Creative Commons Attribution 4.0 International License (http:// creativecommons.org/licenses/by/4.0/), which permits unrestricted use, distribution, and reproduction in any medium, provided you give appropriate credit to the original author(s) and the source, provide a link to the Creative Commons license, and indicate if changes were made.

\section{References}

A4NH. (2011). Agriculture for improved nutrition and health: full proposal. Washington: IFPRI.

A4NH. (2014). Annual Report 2013. Washington DC: IFPRI.

Abdulrazzaq, Y. M., Osman, N., \& Ibrahim, A. (2002). Fatal exposure to aflatoxins in the United Arab Emirates. Annals of Tropical Paediatrics: International Child Health, 22(1), 3-9.

Abdulrazzaq, Y. M., Osman, N., Yousef, Z. M., \& Trad, O. (2004). Morbidity in neonates of mothers who have ingested aflatoxins. Annals of Tropical Paediatrics: International Child Health, 24(2), 145-151.

Abulu, E., Uriah, N., Aigbefo, H., Oboh, P., \& Agbonlahor, D. (1998). Preliminary investigation on aflatoxin in cord blood of jaundiced neonates. West African Journal of Medicine, 17(3), 184.

Afshar, P., Shokrzadeh, M., Kalhori, S., Babaee, Z., \& Saravi, S. S. (2013). Occurrence of Ochratoxin A and Aflatoxin M1 in human breast milk in Sari, Iran. Food Control, 31, 525-529.

Ahmed, H., Hendrickse, R., Maxwell, S., \& Yakubu, A. (1995). Neonatal jaundice with reference to aflatoxins: an aetiological study in Zaria, northern Nigeria. Annals of Tropical Paediatrics, 15(1), 11-20.

Anjaiah, V., Thakur, R. P., \& Koedam, N. (2006). Evaluation of bacteria and Trichoderma for biocontrol of pre-harvest seed infection by Aspergillus flavus in groundnut. Biocontrol Science and Technology, 16, 431-436.

Atehnkeng, J., Ojiambo, P. S., Donner, M., Ikotun, T., Sikora, R. A., Cotty, P. J., \& Bandyopadhyay, R. (2008a). Distribution and toxigenicity of Aspergillus species isolated from maize kernels from three agroecological zones in Nigeria. International Journal of Food Microbiology, 122, 74-84.

Atehnkeng, J., Ojiambo, P. S., Ikotun, T., Sikora, R. A., Cotty, P. J., \& Bandyopadhyay, R. (2008b). Evaluation of atoxigenic isolates of Aspergillus flavus as potential biocontrol agents for aflatoxin in maize. Food Additives and Contaminants, 25, 1264-1271.

Atehnkeng, J., Augusto, J., Cotty, P.J., \& Bandyopadhyay, R. (2013). Developing Aflasafe ${ }^{\mathrm{TM}}$. IITA R4D Review 10: 43-48. (http:// r4dreview.org/wp-content/uploads/2013/09/r4d-review-edition-10march-2012.pdf; accessed on 28 September 2014).

Atehnkeng, J., Ojiambo, P. S., Cotty, P. J., \& Bandyopadhyay, R. (2014). Field efficacy of a mixture of atoxigenic Aspergillus flavus vegetative compatibility groups in preventing aflatoxin contamination in maize (Zea mays L.). Biological Control, 72, 62-70.

Bandyopadhyay, R., \& Cotty, P. J. (2013). Biological controls for aflatoxin reduction. In L. Unnevehr \& D. Grace (Eds.), Aflatoxins:
Finding solutions for improved food safety (pp. 44-45). Washington DC: IFPRI.

Brooks, T. D., Williams, W. P., Windham, G. L., Willcox, M. C., \& Abbas, H. K. (2005). Quantitative trait loci contributing resistance to aflatoxin accumulation in the maize inbred Mp313E. Crop Science, 45, 171-174.

Brown, R. L., Chen, Z. Y., Cleveland, T. E., \& Russin, J. S. (1999). Advances in the development of host resistance in corn to aflatoxin contamination by Aspergillus flavus. Phytopathology, 89(2), 113117.

Busboom, K. N., \& White, D. G. (2004). Inheritance of resistance to aflatoxin production and Aspergillus ear rot of corn from the cross of inbreds B73 and Oh516. Phytopathology, 94(10), 1107-1115.

Cairns, J. E., Crossa, J., Zaidi, P. H., Grudloyma, P., Sanchez, C., Araus, J. L., Makumbi, D., Magorokosho, C., Bänziger, B., Menkir, A., Hearne, S., \& Atlin, G. N. (2013). Identification of drought, heat and combined drought and heat tolerance donors in maize (Zea mays L.). Crop Science, 53, 1335-1346.

Campbell, K. W., \& White, D. G. (1995). Evaluation of corn genotypes for resistance to Aspergillus ear rot, kernel infection, and aflatoxin production. Plant Disease, 79, 1039-1045.

Centers for Disease Control and Prevention (CDC). (2006). Helicobacter pylori and peptic ulcer disease. http://www.cdc.gov/ulcer/economic. htm. Accessed September 9, 2014.

Cotty, P. J. (1994). Influence of field application of an atoxigenic strain of Aspergillus flavus on the populations of $A$. flavus infecting cotton bolls and on the aflatoxin content of cottonseed. Phytopathology, 84, $1270-1277$.

Cotty, P. J., \& Bayman, P. (1993). Competitive exclusion of a toxigenic strain of Aspergillus flavus by an atoxigenic strain. Phytopathology, 83, 1283-1287.

Cotty, P. J., Probst, C., \& Jaime-Garcia, R. (2008). Etiology and management of aflatoxin contamination. In J. F. Leslie, R. Bandyopadhyay, \& A. Visconti (Eds.), Mycotoxins: Detection methods, management, public health and agricultural trade (pp. 287-299). Wallingford: CABI Publishing.

Council for Agricultural Science and Technology (CAST). (2003). Mycotoxins: Risks in plant, animal, and human systems. Ames.

Donner, M., Atehnkeng, J., Sikora, R. A., Bandyopadhyay, R., \& Cotty, P. J. (2010). Molecular characterization of atoxigenic strains for biological control of aflatoxins in Nigeria. Food Additives \& Contaminants: Part A, 27, 576-590.

Egal, S., Hounsa, A., Gong, Y. Y., Turner, P. C., Wild, C. P., Hall, A. J., Hell, K., \& Cardwell, K. F. (2005). Dietary exposure to aflatoxin from maize and groundnut in young children from Benin and Togo, West Africa. International Journal of Food Microbiology, 104(2), 215-224.

El-Tras, W. F., El-Kady, N. N., \& Tayel, A. A. (2011). Infants exposure to aflatoxin $\mathrm{M}_{1}$ as a novel foodborne zoonosis. Food Chemical Toxicology, 49(11), 2816-2819.

Gathura, G. (2011) Study finds 65 p.c. of flour unfit for eating. Daily Nation. 16 March 2011. Accessed online 15 February 2013.

Geiger, H. H. (2009). Doubled Haploids. In J. L. Bennetzen \& S. Hake (Eds.), Maize handbook - volume II: Genetics and genomics (pp. 641-657). New York: Springer Science and Business Media.

Gong, Y. Y., Cardwell, K., Hounsa, A., Egal, S., Turner, P. C., Hall, A. J., \& Wild, C. P. (2002). Dietary aflatoxin exposure and impaired growth in young children from Benin and Togo: cross sectional study. British Medical Journal, 325(7354), 20-21.

Gong, Y. Y., Egal, S., Hounsa, A., Turner, P. C., Hall, A. J., Cardwell, K. F., \& Wild, C. P. (2003). Determinants of aflatoxin exposure in young children from Benin and Togo, West Africa: the critical role of weaning. International Journal of Epidemiology, 32(4), 556-562.

Gong, Y., Hounsa, A., Egal, S., Turner, P. C., Sutcliffe, A. E., Hall, A. J., Cardwell, K., \& Wild, C. P. (2004). Postweaning exposure to aflatoxin results in impaired child growth: a longitudinal study in Benin, 
West Africa. Environmental Health Perspectives, 112(13), 1334 1338.

Grace, D. (2014). The business case for One Health. Onderstepoort Journal of Veterinary Research, 81(2), 725.

Grace, D., Makita, K., Kang'ethe, E. K., \& Bonfoh, B. (2010). Safe food, fair food: participatory risk analysis for improving the safety of informally produced and marketed food in sub-Saharan Africa. Revue Africaine de Santé et de Productions Animales, 8(S), 3-11.

Grace, D., Mutua, F., Ochungo, P., Kruska, R., Jones, K., Brierley, L., Lapar, L., Said, M., Herrero, M., Phuc, P.M., Thao, N.B., Akuku, I., \& Ogutu, F. (2012). Mapping of poverty and likely zoonoses hotspots. Zoonoses Project 4. Report to the UK Department for International Development. Nairobi, Kenya: ILRI

Guantai, S. M. \& Seward, P. (2010) Maize handbook. ACDI/VOCA Kenya Training Manual No. 38. Nairobi, Kenya.

Gürbay, A., Sabuncuoğlu, S. A., Girgin, G., Sahin, G., Yiğit, S., Yurdakök, M., \& Tekinalp, G. (2010). Exposure of newborns to aflatoxin M1 and B1 from mothers' breast milk in Ankara, Turkey. Food and Chemical Toxicology, 48(1), 314-319.

Hoffmann, V., \& Gatobu, K. M. (2014). Growing their own: unobservable quality and the value of self-provisioning. Journal of Development Economics, 106, 168-178.

International Crops Research Institute in the Semi-Arid Tropics (ICRISAT). (2012/2013). Archival Report. ICRISAT Andhra Pradesh, India.

Jiang, Y., Jolly, P. E., Ellis, W. O., Wang, J. S., Phillips, T. D., \& Williams, J. H. (2005). Aflatoxin B1 albumin adduct levels and cellular immune status in Ghanaians. International Immunology, 17(6), 807814

Jonsyn, F., Maxwell, S., \& Hendrickse, R. (1995a). Human fetal exposure to ochratoxin A and aflatoxins. Annals of Tropical Paediatrics, 15(1), 3-9.

Jonsyn, F. E., Maxwell, S. M., \& Hendrickse, R. G. (1995b). Ochratoxin $\mathrm{A}$ and aflatoxins in breast milk samples from Sierra Leone. Mycopathologia, 131(2), 121-126.

Kassam, A., \& Barat, S. (2003). Food safety considerations for CGIAR research. Journal of Agricultural \& Food Information, 5(3), 27-71.

Khlangwiset, P., Shephard, G. S., \& Wu, F. (2011). Aflatoxins and growth impairment: a review. Critical Reviews in Toxicology, 41(9), 740 755 .

Kirimi, L.N., Sitko, T.S., Jayne, F., Karin, M., Muyanga, M.S., Flock J., \& Bor G. (2011). A farm gate to consumer value chain analysis of Kenya's maize marketing system. Egerton University Working Paper Series, 44.

Krska, R., Schubert-Ullrich, P., Molinelli, A., Sulyok, M., MacDonald, S., \& Crews, C. (2008). Mycotoxin analysis: an update. Food Additives and Contaminants, 25(2), 152-163.

Kuniholm, M. H., Lesi, O. A., Mendy, M., Akano, A. O., Sam, O., Hall, A. J., Whittle, H., Bah, E., Goedert, J. J., \& Hainaut, P. (2008). Aflatoxin exposure and viral hepatitis in the etiology of liver cirrhosis in the Gambia, West Africa. Environmental Health Perspectives, 116(11), 1553-1557.

Lammerding, A. M., \& Fazil, A. (2000). Hazard identification and exposure assessment for microbial food safety risk assessment. International Journal of Food Microbiology, 58(3), 147-157.

Lamplugh, S., Hendrickse, R., Apeagyei, F., \& Mwanmut, D. (1988). Aflatoxins in breast milk, neonatal cord blood, and serum of pregnant women. British Medical Journal (Clinical Research Ed.), 296(6627), 968.

Leroy, J. (2013). Child stunting and aflatoxins: Brief 4. In L. Unnevehr \& D. Grace (Eds.), Aflatoxins: Finding solutions for improved food safety (pp. 14-15). Washington DC: IFPRI.

Lewis, L., Onsongo, M., Njapau, H., Schurz-Rogers, H., Luber, G., Kieszak, S., \& Kenya Aflatoxicosis Investigation Group. (2005). Aflatoxin contamination of commercial maize products during an outbreak of acute aflatoxicosis in eastern and central Kenya. Environmental Health Perspectives, 113, 1763-1767.
Lisker, N., \& Lillehoj, E. B. (1991). Prevention of mycotoxin contamination (principally aflatoxins and Fusarium toxins) at the preharvest stage. In J. E. Smith \& R. S. Henderson (Eds.), Mycotoxins in animal foods (pp. 689-719). Boca Raton: CRC Press.

Liu, Y., \& Wu, F. (2010). Global burden of aflatoxin-induced hepatocellular carcinoma: a risk assessment. Environmental Health Perspectives, 118(6), 818-824.

McClintock, A.. \& Griffith, G. R. (2010). Benefit-cost metaanalysis of investment in the International Agricultural Research Centres. Australian Centre for International Agricultural Research.

McMillian, W. W., Wilson, D. M., \& Widstrom, N. W. (1985). Aflatoxin contamination of preharvest maize in Georgia: a six-year study of insect damage and visible Aspergillus flavus. Journal of Environmental Quality, 14, 200-202.

Méaux, S., Pantiora, E., \& Schneider, S. (2013). Aflatoxin management in the World Food Programme through P4P local procurement. International Food Policy Research Institute (IFPRI).

Menkir, A., Brown, R. L., Bandyopadhyay, R., Chen, Z.-Y., \& Cleveland, T. E. (2006). A USA-Africa collaborative strategy for identifying, characterizing, and developing maize germplasm with resistance to aflatoxin contamination. Mycopathologia, 162, 225-232.

Moser, C., Hoffmann, V., \& Ordonez, R. (2014). Firm heterogeneity in food safety provision: evidence from aflatoxin tests in Kenya at the Agricultural \& Applied Economics Association meeting, July 27, 2014.

Murray, C. J., Lopez, A. D., Mathers, C. D., \& Stein, C. (2001). The Global Burden of Disease 2000 project: aims, methods and data sources. Geneva: World Health Organization.

Nigam, S. N., Waliyar, F., Aruna, R., Reddy, S. V., Kumar, P. L., Craufurd, P. Q., Diallo, A. T., Ntare, B. R., \& Upadhyaya, H. D. (2009). Breeding peanut for resistance to aflatoxin contamination at ICRISAT. Peanut Science, 36, 43-49.

Okoth, S. A., \& Ohingo, M. (2004). Dietary aflatoxin exposure and impaired growth in young children from Kisumu District, Kenya: cross sectional study. African Journal of Health Science, 11(1-2), 43-54.

Otsuki, T., Wilson, J. S., \& Sewadeh, M. (2001). Saving two in a billion: quantifying the trade effect of European food safety standards on African exports. Food Policy, 26, 495-514.

Ozimati, A. A., Rubaihayo, P. R., Gibson, P., Edema, R., Kayondo, I. S., Ntare, B. R., \& Okello, D. K. (2014). Inheritance of resistance to kernel infection by Aspergillus flavus and aflatoxin accumulation in groundnut. African Journal of Crop Science, 2, 51-59.

Pal, K. K., \& McSpadden-Gardener, B. (2006). Biological control of plant pathogens. The Plant Health Instructor. doi:10.1094/PHI-A2006-1117-02.

Pandey, M. K., Guo, B., Holbrook, C. C., Janila, P., Zhang, X., Bertioli, D. J., Isobe, S., Liang, X., \& Varshney, R. K. (2014). Molecular markers, genetic maps and QTLs for molecular breeding in peanut. In N. Malikarjuna \& R. K. Varshney (Eds.), Genetics, genomics and breeding of peanuts (pp. 61-113). New York: CRC Press, Taylor and Francis Group.

Paul, C., Naidoo, G., Forbes, A., Mikkilineni, V., White, D., \& Rocheford, T. (2003). Quantitative trait loci for low aflatoxin production in two related maize populations. Theoretical Applied Genetics, 107, 263-270.

Perry, B. D., Randolph, T. F., McDermott, J. J., Sones, K. R., \& Thornton, P. K. (2002). Investing in animal health research to alleviate poverty. Nairobi: ILRI.

Polychronaki, N., Turner, P., Mykkänen, H., Gong, Y., Amra, H., AbdelWahhab, M., \& El-Nezami, H. (2006). Determinants of aflatoxin M1 in breast milk in a selected group of Egyptian mothers. Food Additives \& Contaminants, 23(7), 700-708.

Polychronaki, N., West, R. M., Turner, P. C., Amra, H., AbdelWahhab, M., Mykkänen, H., \& El-Nezami, H. (2007). A longitudinal assessment of aflatoxin M1 excretion in breast 
milk of selected Egyptian mothers. Food and Chemical Toxicology, 45(7), 1210-1215.

Polychronaki, N., Wild, C. P., Mykkänen, H., Amra, H., AbdelWahhab, M., Sylla, A., Diallo, M., El-Nezami, H., \& Turner, P. C. (2008). Urinary biomarkers of aflatoxin exposure in young children from Egypt and Guinea. Food and Chemical Toxicology, 46(2), 519-526.

Rao, M. J. V., Upadhyaya, H. D., Mehan, V. K., Nigam, S. N., McDonald, D., \& Reddy, N. S. (1995). Registration of peanut germplasm ICGV 88145 and ICGV 89104 resistant to seed infection by Aspergillus flavus. Crop Science, 35, 1717.

Renkow, M., \& Byerlee, D. (2010). The impacts of CGIAR research: a review of recent evidence. Food Policy, 35(5), 391-402.

Ricci, K. A., Girosi, F., Tarr, P. I., Lim, Y. W., Mason, C., Miller, M., \& Guerrant, R. L. (2006). Reducing stunting among children: the potential contribution of diagnostics. Nature, 444, 29-38.

Roy, D. (2013). Trade impacts of aflatoxin standards, Brief 12. In L. Unnevehr \& D. Grace (Eds.), Aflatoxins: Finding solutions for improved food safety (pp. 33-34). Washington DC: IFPRI.

Sadeghi, N., Oveisi, M., Jannat, B., Hajimahmoodi, M., Bonyani, H., \& Jannat, F. (2009). Incidence of aflatoxin M1 in human breast milk in Tehran, Iran. Food Control, 20, 75-78.

Shotwell, L., \& Hesseltine, C. W. (1981). Use of bright greenish- yellow fluorescence as a presumptive test for aflatoxin in corn. Cereal Chemistry, 53, 124-127.

Sodeinde, O., Chan, M., Maxwell, S., Familusi, J., \& Hendrickse, R. (1995). Neonatal jaundice, aflatoxins and naphthols: report of a study in Ibadan, Nigeria. Annals of Tropical Paediatrics, 15(2), 107.

Tchana, A. N., Moundipa, P. F., \& Tchouanguep, F. M. (2010). Aflatoxin contamination in food and body fluids in relation to malnutrition and cancer status in Cameroon. International Journal of Environmental Research and Public Health, 7(1), 178-188.

Technical Advisory Committee (TAC). (2000). A food secure world for all: Towards a new vision and strategy for the CGIAR. Rome: TAC Secretariat, FAO.

Thakur, R. P., Rao, V. P., Reddy, S. V., \& Ferguson, M. (2000). Evaluation of wild Arachis germplasm accessions for in vitro seed colonization and aflatoxin production by Aspergillus flavus. International Arachis Newsletter, 20, 44-46.

Turner, P. C., Mendy, M., Whittle, H., Fortuin, M., Hall, A. J., \& Wild, C. P. (2000). Hepatitis B infection and aflatoxin biomarker levels in Gambian children. Tropical Medicine \& International Health, 5(12), 837-841.

Turner, P. C., Moore, S. E., Hall, A. J., Prentice, A. M., \& Wild, C. P. (2003). Modification of immune function through exposure to dietary aflatoxin in Gambian children. Environmental Health Perspectives, 111(2), 217.

Turner, P. C., Collinson, A. C., Cheung, Y. B., Gong, Y., Hall, A. J., Prentice, A. M., \& Wild, C. P. (2007). Aflatoxin exposure in utero causes growth faltering in Gambian infants. International Journal of Epidemiology, 36(5), 1119-1125.

Upadhyaya, H. D., Nigam, S. N., Mehan, V. K., Reddy, A. G. S., \& Yellaiah, N. (2001). Registration of Aspergillus flavus seed infection resistant peanut germplasm ICGV 91278, ICGV 91283, and ICGV 91284. Crop Science, 41, 598-599.

Upadhyaya, H.D., Nigam, S.N., \& Waliyar, F. (2003). Aflatoxin contamination in groundnut: Conventional breeding for resistance. Proc. of the 3rd Fungal Genomics, 4th Fumonisin, and 16th Aflatoxin
Elimination Workshops. Oct 13-15, 2003. Savannah, Georgia USA. pp. 55 (abstract).

Vose, D. (1998). The application of quantitative risk assessment to microbial food safety. Journal of Food Protection, 61(5), 640-648.

Vries, H. D., Maxwell, S., \& Hendrickse, R. (1989). Foetal and neonatal exposure to aflatoxins. Acta Paediatrica, 78(3), 373-378.

Waliyar, F., Hassan, H., Bonkoungou, S., \& Bosc, J. K. (1994). Sources of resistance to Aspergillus flavus and aflatoxin contamination in groundnut genotypes in West Africa. Plant Disease, 78, 704-708.

Waliyar, F., Reddy, S.V., \& Kumar, P.L. (2005). Estimation of Aspergillus flavus infection and aflatoxin contamination in seeds: Laboratory manual. ICRISAT (International Crops Research Institute for the Semi-Arid Tropics), $26 \mathrm{pp}$. Patancheru, A.P. 502 324, India.

Warburton, M. L., Brooks, T. D., Windham, G. L., \& Williams, W. P. (2011). Identification of QTL 590 contributing resistance to aflatoxin accumulation in maize. Molecular Breeding, 27, 491-499.

Warfield, C. Y., \& Davis, R. M. (1996). Importance of the husk covering on the susceptibility of corn hybrids to Fusarium ear rot. Plant Disease, 80, 208-210.

Widstrom, N. W. (1987). Breeding strategies to control aflatoxin contamination of maize through host plant resistance. In M. S. Zuber, E. B. Lillehoj, \& B. L. Renfro (Eds.), Aflatoxin in maize: Proc. workshop (pp. 212-220). Mexico: CIMMYT.

Widstrom, N. W., Butron, A., Guo, B. Z., Wilson, D. M., Snook, M. E., Cleveland, T. E., \& Lynch, R. E. (2003). Control of pre-harvest aflatoxin contamination in maize by pyramiding QTLs involved in resistance to ear feeding insects and invasion by Aspergillus spp. European Journal of Agronomy, 19(4), 563-572.

Wild, C., Jiang, Y. Z., Allen, S., Jansen, L., Hall, A., \& Montesano, R. (1990). Aflatoxin - albumin adducts in human sera from different regions of the world. Carcinogenesis, 11(12), 2271-2274.

Wild, C. P., Fortuin, M., Donato, F., Whittle, H. C., Hall, A. J., Wolf, C. R., \& Montesano, R. (1993). Aflatoxin, liver enzymes, and hepatitis $\mathrm{B}$ virus infection in Gambian children. Cancer Epidemiology, Biomarkers \& Prevention, 2(6), 555-561.

Willcox, M. C., Davis, G. L., Warburton, M. L., Windham, G. L., Abbas, H. K., Betran, J., Holland, J. B., \& Williams, W. P. (2013). Confirming quantitative trait loci for aflatoxin resistance from $\mathrm{Mp} 313 \mathrm{E}$ in different genetic backgrounds. Molecular Breeding, 32(1), 15-26.

Wu, F., \& Khlangwiset, P. (2010a). Health economic impacts and costeffectiveness of aflatoxin reduction strategies in Africa: case studies in biocontrol and post-harvest interventions. Food Additives \& Contaminants: Part A, 27, 496-509.

Wu, F., \& Khlangwiset, P. (2010b). Evaluating the technical feasibility of aflatoxin risk reduction strategies in Africa. Food Additives and Contaminants, 27(5), 658-676.

Xiong, B. \& Beghin, J. (2010). Aflatoxin redux: does European aflatoxin regulation hurt groundnut exporters from Africa?. Staff General Research Papers, 31595.

Xue, H. Q., Isleib, T. G., Payne, G. A., \& O’Brian, G. (2004). Evaluation of post-harvest aflatoxin production in peanut germplasm with resistance to seed colonization and preharvest aflatoxin contamination. Peanut Science, 31, 124-134.

Zhou, G. Y., Liang, X. Q., Li, Y. C., Li, S. X., \& Li, S. L. (2002). Evaluation and application of introduced peanut cultivars for resistance to Aspergillus flavus invasion. Journal of Peanut Science, 34, 14-17. In Chin, Abstr. In En. 


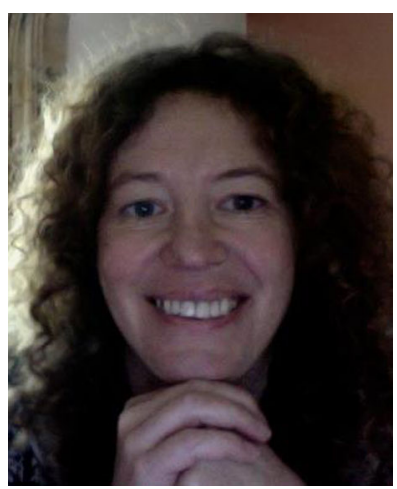

Delia Grace Delia is an epidemiologist and veterinarian with 20 years experience in developing countries. She leads research on zoonoses and foodborne disease at the International Livestock Research Institute in Kenya and in the CGIAR Research Program on Agriculture for Human Nutrition and Health led by IFPRI. Research interests include emerging diseases, participatory epidemiology, gender and animal welfare. Her career has spanned the private sector, field-level community development and aid management, as well as research. She has lived and worked in Asia, west and east Africa and authored or co-authored more than 100 peer-reviewed publications as well as, briefs, films, articles and blog posts.

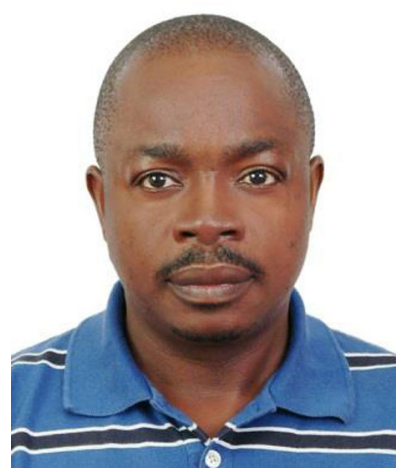

George Mahuku George Mahuku is from Zimbabwe, is the Senior Plant Pathologist for Eastern, Southern and Central Africa with the International Institute of Tropical Agriculture. His research activities include disease epidemiology, pathogen characterization, surveillance / monitoring for new and / or emerging diseases and quantifying the effect of climate change on maize diseases. $\mathrm{He}$ has been working on documenting the incidence and prevalence of mycotoxins in maize and identifying and deploying the crop's resistance to mycotoxin contamination. George has lived and worked in Canada, Colombia, Mexico and currently in Tanzania.

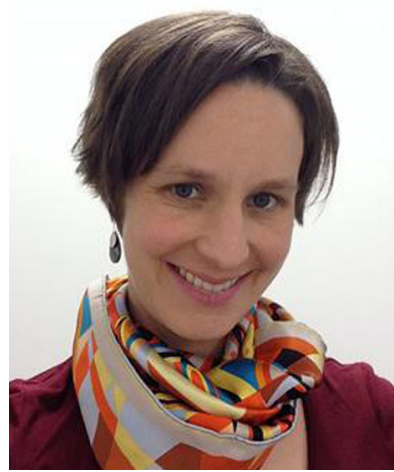

Vivian Hoffmann Vivian Hoffmann is a micro-economist and Research Fellow at the International Food Policy Research Institute, where she leads research on food and water safety. Her research concerns how markets and institutions in developing countries affect public health outcomes. Hoffmann's published work includes studies on consumer demand for a broad range of health-related goods, including safe food and water. Current research includes one randomized intervention trial investigating the impact of aflatoxin on child growth, another testing the impact of price incentives on farmer practices and aflatoxin contamination, and a study characterizing consumers' responses to third party labeling for aflatoxin safety.

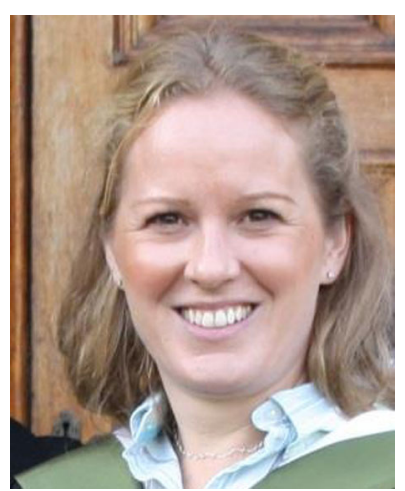

Christine Atherstone Christine Atherstone is a $\mathrm{PhD}$ candidate at the University of Sydney, Australia studying the impact of emerging infectious diseases on livestock production, public health and human livelihoods. She works for ILRI in the Food Safety \& Zoonoses group in Uganda where she has lived for 9 years. Her current work includes identifying the role domestic pigs play in Ebola virus transmission in Uganda. Christine previously studied at the University of Edinburgh in the Global Health Academy where she first confirmed the presence of leptospirosis in wildlife and domestic livestock in Uganda, which was published in the American Journal of Tropical Medicine and Hygiene.

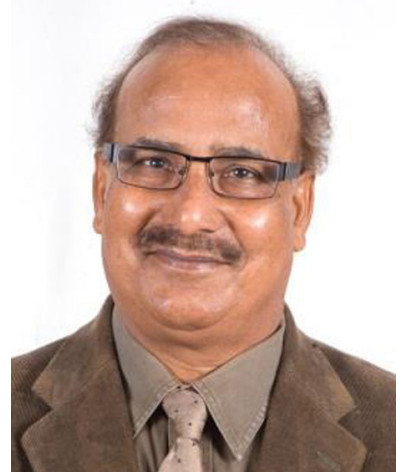

Hari D Upadhyaya Hari D Upadhyaya, Director Genebank and Principal Scientist, ICRISAT is an eminent scientist with over 35 years teaching and research experience of working on legumes (genetics, breeding, germplasm) and cereals (genetics, germplasm). He is also an Adjunct Professor at Kansas State University, Manhattan, USA, and University of Western Australia, Crawley, Australia. Dr Upadhyaya is Fellow of the American Society of Agronomy, the Crop Science Society of America (CSSA), Honorary Fellow of the Indian Society of Plant Genetic Resources, and recipient of many honours and awards including the Frank N Meyer Medal for Plant Genetic Resources, the Crop Science Research Award, and the International Service in Crop science Award from CSSA for his outstanding contributions to crop science and plant genetic resources, which are of global significance. He has authored more than 700 publications including over 280 peer-reviewed journal articles and review papers. He has also been responsible for 44 groundnut varieties released in 22 countries.

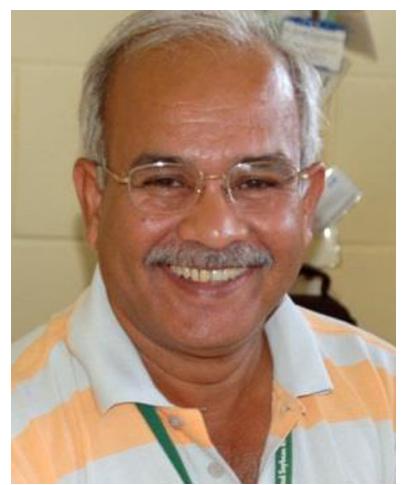

Ranajit Bandyopadhyay Ranajit Bandyopadhyay is a plant pathologist with 35 years of research and development experience in Asia, Africa and the Americas. He guides research and development activities related to crop diseases and mycotoxins at the International Institute of Tropical Agriculture. Ranajit leads Africawide efforts on development and scaling-up of the aflatoxin biocontrol technology aflasafe. His research on mycotoxins focuses on surveillance, bio-ecology of toxigenic fungi, integrated management of mycotoxins and policy and institutional issues. Ranajit has authored nearly 175 publications. He is a member of the Steering Committee of the Partnership for Aflatoxin Control in Africa and chairs its Technical Sub-Committee. 